\title{
Morfologia externa do adulto de Almeidaia aidae Mielke \& Casagrande (Lepidoptera, Saturniidae, Arsenurinae, Almeidaiini). II. Tórax e apêndices ${ }^{1}$
}

\author{
Amabílio J. A. de Camargo ${ }^{2}$, Mirna M. Casagrande ${ }^{3}$, Olaf H. H. Mielke ${ }^{3} \&$ Eurides Furtado ${ }^{4}$ \\ ${ }^{1}$ Contribuição número 1540 do Departamento de Zoologia, Universidade Federal do Paraná. \\ 2 Embrapa Cerrados. Rodovia BR 020, Km 18, Caixa postal 08223, 73310-970 Brasília, Distrito Federal, Brasil. E-mail: \\ amabílio@cpac.embrapa.br \\ ${ }_{3}^{3}$ Departamento de Zoologia, Universidade Federal do Paraná. Caixa Postal 19020, 81531-980 Curitiba, Paraná, Brasil. \\ Pesquisador do CNPq.E-mail: omhesp@ufpr.br; mibras@ufpr.br \\ ${ }^{4}$ Caixa Postal 97, 78400-000 Diamantino, Mato Grosso, Brasil.
}

\begin{abstract}
External morphology of Almeidaia aidae Mielke \& Casagrande (Lepidoptera, Saturniidae, Arsenurinae, Almeidaiini). II. Thorax and appendages. The external morphology of adult thorax and appendages of Almeidaia aidae Mielke \& Casagrande, 1981 is described and illustrated for the first time. The results obtained were compared with other species of Saturniidae. This species is rare and endemic of the Cerrado region. Biological studies were published by the fourth author. This is the second of a series of papers about the morphology of the species.
\end{abstract}

KEY WORDS. Brazil, Cerrado region, moth, Neotropical.

RESUMO. A morfologia externa do tórax e apêndices de Almeidaia aidae Mielke \& Casagrande, 1981 é descrita e ilustrada pela primeira vez. Os resultados obtidos foram comparados com outras espécies de Saturniidae. É uma espécie rara e endêmica da região do Cerrado. Estudos sobre sua biologia foram publicados pelo quarto autor. Esta é a segunda contribuição sobre a espécie.

PALAVRAS CHAVE. Brasil, mariposa, Neotropical, região do Cerrado.

Dentre os lepidópteros de hábitos noturnos, os saturnídeos possivelmente sejam os mais estudados, no entanto, faltam informações sobre a biologia, morfologia e distribuição para a maioria das espécies. Os estudos morfológicos são particularmente importantes para o esclarecimento das relações filogenéticas do grupo. Este é o segundo de três artigos que pretendem esclarecer a morfologia de Almeidaia aidae, uma das espécies menos conhecida dentre os Arsenurinae brasileiros.

O gênero Almeidaia Travassos, 1937 compreende apenas duas espécies ainda pouco estudadas e raras nas coleções. A espécie tipo, Almeidaia romualdoi Travassos, 1937, foi descrita com base em um único exemplar macho proveniente (conforme etiqueta do holótipo) de: Eugênio Lefevre, Campos do Jordão (localidade atualmente situada no município de Santo Antonio do Pinhal), São Paulo, 1200 m, capturado em 1.XI.1937 por L. Travassos, J. Oiticica, L. Travassos Filho e H. Lopes, dados estes incompletos na descrição original. Desde sua descrição nenhum outro exemplar foi coletado e a fêmea continua desconhecida. A outra espécie do gênero e objeto desse estudo, Almeidaia aidae Mielke \& Casagrande,1981 foi descrita a partir de exemplares da coleção Gagarin que haviam sido confundi- dos com a espécie anterior (Gagarin 1966, Mielke \& Casagrande 1981). A fêmea de $A$. aidae foi equivocadamente ilustrada e descrita por Lemaire (1980) como sendo de A. romualdoi. Para maiores detalhes veja CAMARGO et al. (2005).

\section{MATERIAL E MÉTODOS}

A metodologia seguida foi similar à do estudo da cabeça (CAMARGo et al. 2005), tanto para a nomenclatura empregada quanto para obtenção e processamento do material. Os exemplares utilizados nesse estudo são provenientes de criações realizadas pelo quarto autor em Diamantino, Mato Grosso.

Com exceção das asas, que foram removidas anteriormente, os espécimes foram imersos em uma solução de $\mathrm{KOH}$ 10\% (hidróxido de potássio) e fervidos em banho-maria durante aproximadamente 10 minutos. Uma vez fervidas, as peças foram limpas com uma solução desengordurante contendo $50 \%$ acetona, 30\% de água destilada e $20 \%$ de álcool. Após a limpeza final, a peças foram coloridas, durante cinco minutos em mercúrio cromo 1\% (diluído em água) para facilitar a visualização dos limites entre as áreas membranosas e as pouco esclerotinizadas. O excesso de corante foi removido com a so- 
lução desengordurante durante cinco minutos, com posterior separação das estruturas e seus apêndices para confecção das ilustrações. Adaptou-se o tempo de fervura, corante e solução para limpeza, a partir de técnicas usuais para microlepidóptera descritos em Hogue (1963) e Robinson (1976). Apesar dos corantes serem utilizados na preparação de genitálias, este método se mostrou vantajoso também para outras estruturas morfológicas em Saturniidae.

Para análise da venação, as asas foram imersas em álcool $70 \%$, posteriormente em hipoclorito de sódio 20\% (água sanitária comercial) até a diafanização e em seguida, lavadas com água destilada, conforme descrito em CASAGRANDE (1979a) e BIZARRO et al. (2003).

As ilustrações foram feitas com auxílio de microscópio estereoscópio, com câmara clara acoplada. Para a conservação das estruturas foi utilizado GFA, um preparado com $45 \%$ de glicerina, 5\% de ácido fênico e 50\% de água destilada, conforme citado em CASAGRANDE (1979b). A escala utilizada para cada desenho representa $1 \mathrm{~mm}$, exceto para as asas $(1 \mathrm{~cm})$.

As estruturas torácicas foram descritas com base na literatura específica para Saturniidae (Michener 1952, Lemaire 1971), e quando a terminologia pareceu ser mais adequada, foi utilizada uma literatura mais geral, seguindo principalmente MADDEN (1944), Beutelspacher (1967), Casagrande (1979a,b), Bizarro et al. (2003). A venação foi descrita conforme СомSTоск (1918).

\section{RESULTADOS E DISCUSSÃO}

\section{Tórax}

Estudos morfológicos desse grupo de insetos são escassos na literatura. Assim, a morfologia de Almeidaia aidae foi comparada, em seus aspectos mais gerais, com Eacles imperialis (Drury, 1773) (Ceratocampinae), estudada por Michener (1952), e com Automeris postalbida Schaus, 1900 (Hemileucinae) por Lemaire (1971).

O tórax é articulado com a cabeça através de uma área membranosa e por um par de escleritos cervicais. Com exceção da venação das asas anteriores, $A$. aidae não apresenta dimorfismo sexual na região torácica, e as estruturas ilustradas referem-se a exemplares machos.

\section{Protórax (Figs 1-2)}

Formado pelo pronoto, estrutura alongada, com uma área antero-central mais esclerotinizada em forma de "v" invertido. Na parte anterior com duas projeções semitriangulares, e a porção posterior que articula com o mesótórax, mais estreita. É formado ainda, por um par de patágios, estruturas reniformes desenvolvidas, unidas lateralmente ao pronoto e, um par de parapatágios membranosos, localizados ao longo das laterais do pronoto, desde a base dos patágios até o prescuto II, não visíveis lateralmente, por se encontrarem encobertos pelo préscuto I. Na região posterior da pró-pleura e internamente à área membranosa, o furcasterno se projeta como um esclerito proeminente e desenvolvido, com um prolongamento que al- cança o catepisterno II. Em vista ventral (Fig. 3) a furca surge como um esclerito estreito e esclerotinizado, terminando de modo bifurcado no espinasterno, em posição oposta e com a mesma forma está o basisterno. Ainda na área membranosa intersegmental entre o pró e mesotórax, localizado acima do furcasterno, encontra-se o espiráculo I, em forma de fenda ovalada, posicionada verticalmente.

O tórax de $A$. aidae apresenta muitas semelhanças com outras espécies como Hemileucinae e Ceratocampinae, especialmente em estruturas como pronoto, escuto II e a linha mesoescutal, embora existam diferenças significativas em outras. Patágios de tamanho maior e de forma globosa, contrastam com os encontrados em Eacles imperialis e Automeris postalbida que são alongados e estreitos. Parapatágios membranosos, estreitos e unidos ao pronoto, enquanto nas outras espécies acima comparadas, tem forma e tamanho semelhante ao patágio.

Prescuto II largo, de forma heptagonal e com prolongamentos laterais destacados, ao contrário das outras espécies onde aparece de forma muito mais discreta ou com tamanho extremamente reduzido.

\section{Mesotórax (Figs 1-3).}

Ocupa mais de dois terços do comprimento total do tórax, formado por quatro escleritos distintos: prescuto, escuto, escutelo, pós-noto e apêndices.

Prescuto II, visível apenas em vista dorsal do tórax (Fig. 2), constitui-se de um esclerito heptagonal com projeções pontiagudas laterais, paralelas à parte anterior do escuto.

O segundo esclerito do mesonoto, o maior, é o escuto II, alongado, ligeiramente mais largo na porção média-anterior, com linha mesoescutal completa, esclerotinizada e bem marcada em toda extensão. Localizadas nas porções ântero-laterais ao escuto e inferiormente as tégulas (Figs 1-4), as placas suralares, estreitas e discretas, que se estendem a cada lado desde o braço tegular até a porção mediana do escuto. Entre o escuto II e o escutelo II, látero-ventralmente estão as placas pós-alares do epimero II, cada placa com duas expansões apicais dirigidas anteriormente, os processos notais posteriores II, cuja função é a articulação com os escleritos axilares (Fig. 2).

O escutelo II, hexagonal é separado do escuto II pela sutura escuto-escutelar II. Lateralmente ao escutelo estão as cordas axilares, e posteriormente o pós-noto II, que se constitui de uma estreita área esclerotinizada, circundada por área membranosa.

A sutura pleural II divide a mesopleura em duas partes, uma anterior, o episterno II dividido pela sutura anepistermal II em anepisterno II dorsalmente e catepisterno II ventralmente, e outra posterior, o epimero II não dividido. O catepisterno II é limitado posteriormente pela sutura marginopleural II, anteriormente pelo pré-episterno e posteriormente pelo epimero. A sutura pré-coxal apresenta-se como uma discreta linha delimitando o pré-episterno, estreito e alongado. Mero e eucoxa II, separados pela sutura coxal II, uma linha fortemente marcada e esclerotinizada. 


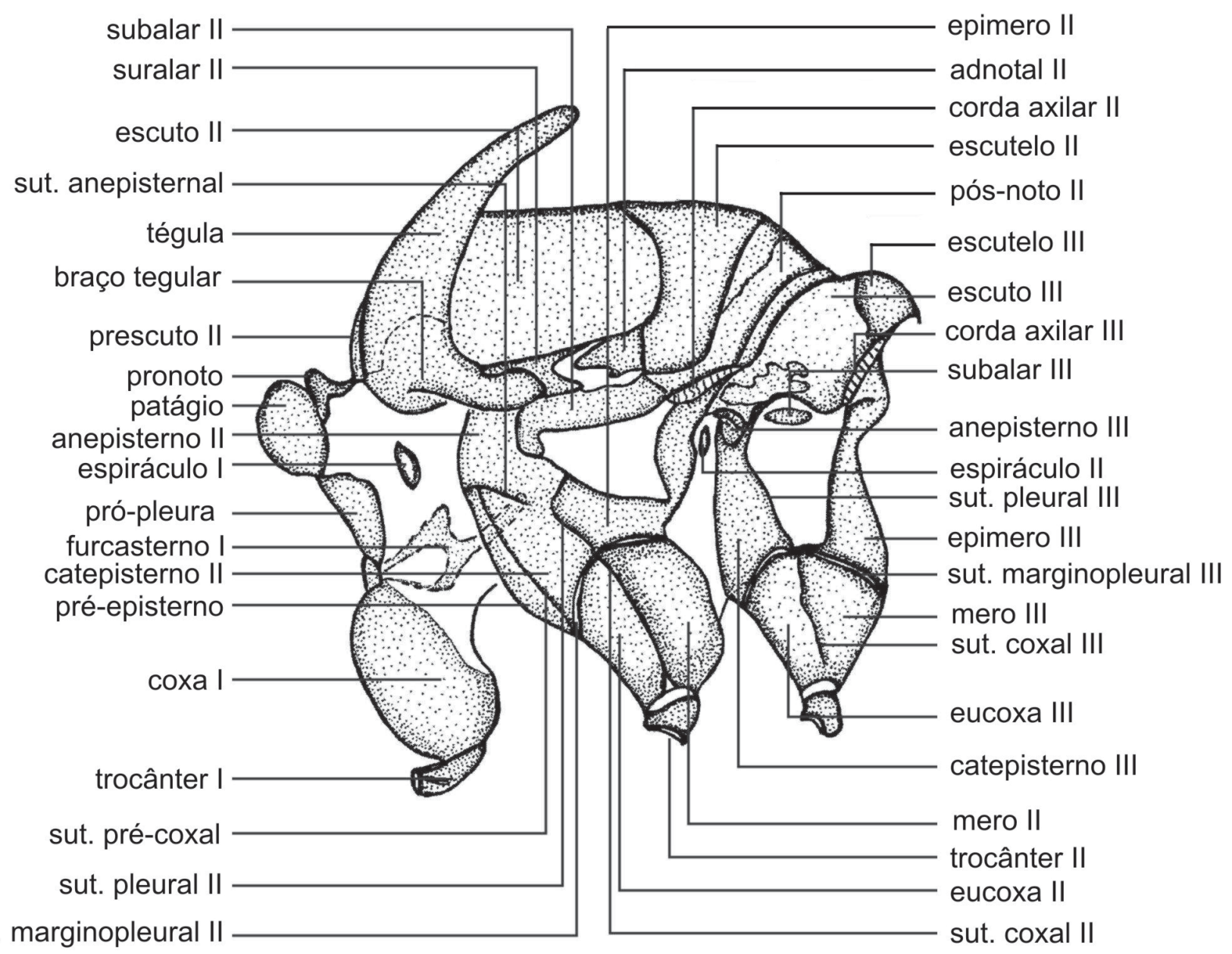

sut. marginopleural II

sut. coxal II

Figura 1. Tórax, vista lateral.

Em vista ventral do mesotórax (Fig. 3), entre as coxas, destaca-se o discrime II que se prolonga até os alvéolos coxais II.

\section{Metatórax (Figs 1-3)}

O metanoto é formado pelo escuto, escutelo, pós-noto e apêndices.

Escuto III formado por dois escleritos alongados, localizados dorsolateralmente e unidos por pequena região na anterior e mediana do escutelo III e separado deste pela sutura escuto-escutelar III. O processo notal anterior III, que articula com o primeiro esclerito axilar, apresenta-se como uma simples projeção da extremidade anterior do escuto III.

Escutelo III em forma de placa semitriangular em cujas extremidades laterais estão as cordas axilares III, como extensões que se prolongam até a pleura.

O pós-noto III (Fig. 2), posterior ao escutelo III, é formado por uma estreita barra esclerotinizada, cuja porção posterior é responsável pela junção do tórax com o abdome.
A sutura pleural III divide a metapleura em duas partes: uma anterior, o episterno III, dividido pela sutura anepisternal III em anepisterno III diminuto e catepisterno III maior, e outra posterior, o epimero III. O catepisterno III está limitado posteriormente por uma área membranosa que alcança o epimero III. Mero e eucoxa III são separados pela sutura coxal III desde a sutura marginopleural III até próximo ao trocânter.

Em vista ventral (Fig. 3), a eucoxa e o mero III formam um conjunto globoso, separados pela sutura coxal, no centro destaca-se o discrime III, representado por uma faixa estreita e esclerotinizada até os alvéolos coxais.

Tégulas (Fig. 4)

Largas, falciformes e acopladas ao mesonoto, com algumas cerdas na porção posterior.

\section{Asas anteriores (Figs 5-6)}

Totalmente diferentes das demais espécies do grupo no que diz respeito à coloração. Enquanto na maioria dos 


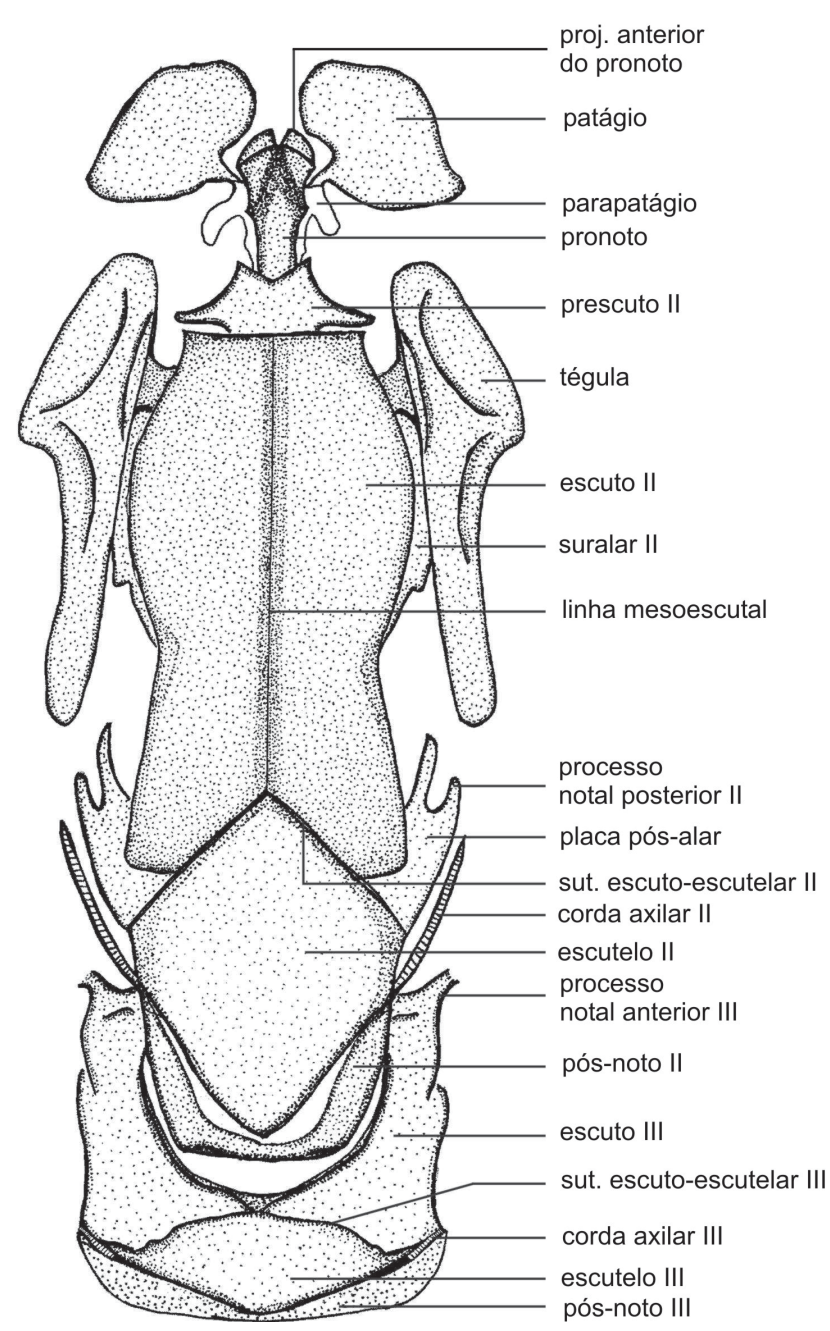

Figura 2. Tórax, vista dorsal.

Arsenurinae a cor de fundo é cinza ou marrom, nessa espécie a cor predominante é laranja no seu terço apical e bege com aparência semitransparente no terço basal. Estreitas, alongadas e de ápice afilado, diferente dos demais Saturniidae que apresentam ápice arredondado ou retilíneo. Nos machos são significativamente maiores e mais estreitas que nas fêmeas.

Subcosta (Sc) se estende da base até aproximadamente 3/4 do comprimento total da margem anterior. Rádio (R), com quatro ramificações $\left(R_{1}, R_{2}, R_{3+4}\right.$ e $\left.R_{5}\right)$, com exceção de $R_{1}$ que surge na primeira bifurcação, no quinto distal da célula, as demais radiais continuam em eixo comum a partir do ápice desta, logo adiante a segunda bifurcação forma um ramo comum para $\mathrm{R}_{2} \mathrm{e}$ $\mathrm{R}_{3+4}$ e outro ramo para $\mathrm{R}_{5}$, sendo que $\mathrm{R}_{3+4}$ terminam no ápice da asa, enquanto $R_{2}$ no espaço entre $R_{1}$ e $R_{3+4}$, mais próxima da primeira que desta Quanto ao número de veias radiais assemelhase a outros Arsenurinae, ou seja, com quatro, enquanto que as outras espécies comparadas apresentam três. Média $(\mathrm{M})$, com três ramificações $\left(M_{1}, M_{2}\right.$ e $\left.M_{3}\right)$ desde a porção distal da célula discal até a margem externa. $\mathrm{M}_{1}$, nos machos, inicialmente fundida ao ramo comum de $\mathrm{R}_{2}$. $\mathrm{R}_{5}$ enquanto nas fêmeas a bifurcação é imediata, em E. imperialis, esta anastomose está presente em ambos os sexos e portanto, em ambos os casos falta a veia transversal disco celular superior (dcs).

Cubital anterior divide-se logo após a metade da célula em $\mathrm{CuA}_{1}$ e $\mathrm{CuA}_{2}$, a primeira termina na margem externa e a segunda na extremidade inferior da mesma margem próxima ao ângulo anal.

As Anais (A), partem paralelas da base, sendo que logo após a origem, a veia $3 \mathrm{~A}$ se funde com a $2 \mathrm{~A}$ que se estende até a região do ângulo anal.

A célula discal é limitada na sua porção anterior pela veia $\mathrm{R}$, posteriormente pela $\mathrm{CuA}$ e é fechada por três transversais: disco-celular mediana (dcm), disco-celular inferior (dci) e médio-cubital (m-cu).

\section{Asas posteriores (Fig. 7)}

De cor amarelo-claro semitransparente, padrão não encontrado nos demais Saturniidae. Algumas espécies da subfamília Arsenurinae apresentam um prolongamento em forma de cauda nas asas posteriores, caráter ausente em Almeidaia.

Semi-arredondadas e sem dimorfismo sexual, pouco mais longas do que largas. A venação compreende a Subcosta fundida com $\mathrm{R}_{1}\left(\mathrm{Sc}+\mathrm{R}_{1}\right)$, paralelas à margem costal. Setor Radial (Rs) como veia única desde a base até o ápice da asa. Média (M), com três ramos $\left(M_{1}, M_{2}, M_{3}\right)$ que partem da célula discal e alcançam a margem externa; $\mathrm{M}_{3}$ anastomosada com $\mathrm{CuA}_{1}$ até $1 / 3$ de sua extensão total; $\mathrm{CuA}_{2}$ se bifurca a $1 / 3$ antes do término da célula e atinge a margem externa, próxima ao ângulo anal. As anais (2A e $3 \mathrm{~A})$ partem paralelas, sendo que a primeira é mais longa e atinge o angulo anal, enquanto que a $3 \mathrm{~A}$ é mais curta, atingindo cerca da metade do comprimento total da margem interna não chegando até ela.

\section{Pernas (Figs 8-12)}

Perna protorácica com coxa alongada que se articula na base com a propleura e com o fêmur através do trocânter. Fêmur alongado, maior que a coxa e semicilíndrico, anteriormente curvado. Tíbia com uma projeção acentuada em forma de espinho na porção apical, o que se constitui um caráter apomórfico para a tribo Almeidaiini. Epífise tibial larga, flexível e pouco esclerotinizada. Tarso com espinhos e cinco tarsômeros, sendo o primeiro o maior e igual a soma dos três seguintes (Fig. 8).

Pernas meso e metatorácicas semelhantes em forma, sendo a perna metatorácica maior. Apresentam coxas arredondadas, divididas por sutura que separa a eucoxa do mero. Em ambas as pernas, o femur é cilíndrico, pouco mais largo que a tíbia, também cilíndrica. Ambas as pernas apresentam um par de esporões tibiais apicais pontiagudos como um espinho. Os esporões medianos das pernas metatorácicas estão ausentes 

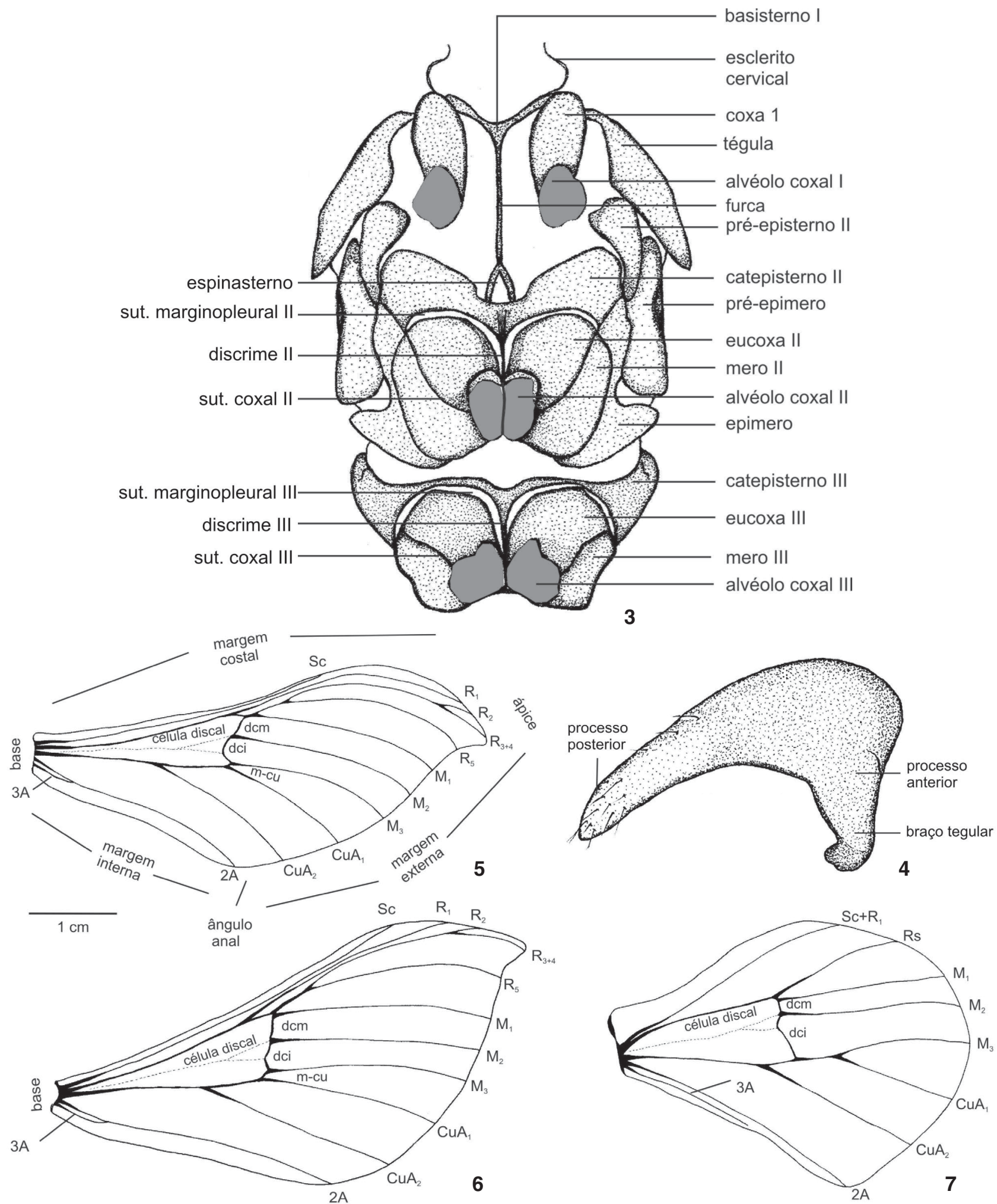

Figuras 3-7. (3)Tórax, vista ventral; (4) tégula; (5) asa anterior do macho; (6) asa anterior da fêmea; (7) asa posterior.

Revista Brasileira de Zoologia 22 (4): 1152-1158, dezembro 2005 

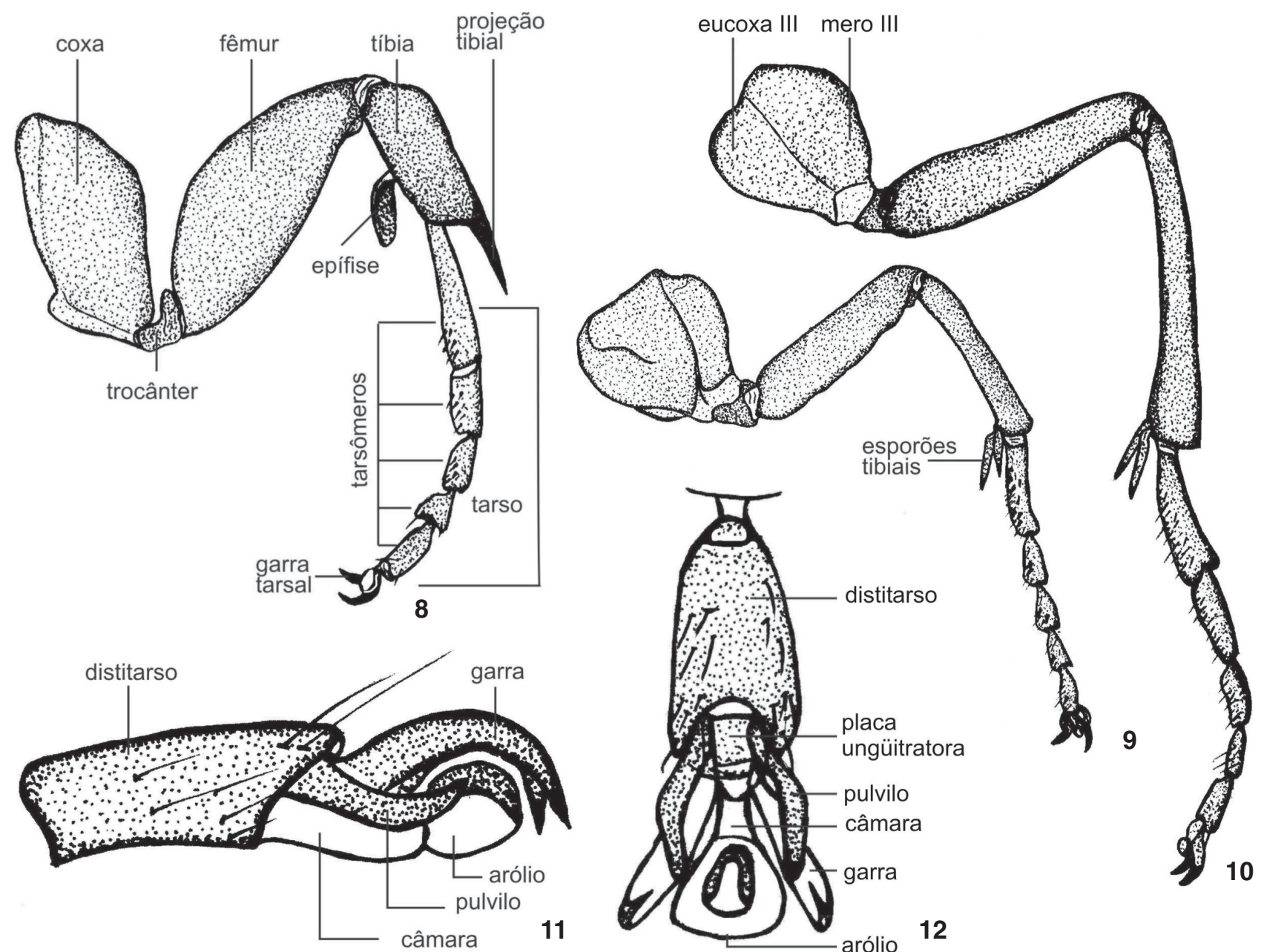

11

Figuras 8-12. Pernas: (8) protorácica; (9) mesotorácica; (10) metatorácica; (11-12) distitarso da perna metatorácica: (11) vista lateral; (12) vista ventral.

nessa espécie. Esta característica é apresentada por muitos Saturniidae e foi considerada por MichENER (1952) como plesiomórfica, mas aparece em várias espécies de Hemileucinae, consideradas pelo mesmo autor como sendo um grupo apical. Entre as subfamílias que ocorrem no Brasil, além dos Hemileucinae, o caráter está presente também em Oxyteninae e alguns Arsenurinae. Tarsos divididos em cinco tarsômeros com espinhos, sendo que o primeiro de maior tamanho, igual à somatória dos dois seguintes (Figs 9-10).

\section{Distitarso (Figs 11-12)}

O distitarso, ou tarsômero distal é semelhante nos três pares de pernas, tanto no macho quanto na fêmea. Apresenta cerdas longas, especialmente na sua porção distal, área onde se conecta com o par de garras tarsais; pulvilos, câmara e arólio com área esclerotinizada na face superior.

\section{AGRADECIMENTOS}

À Empresa Brasileira de Pesquisa Agropecuária - Embrapa, especialmente ao Centro de Pesquisa Agropecuária dos Cerrados - CPAC, que proporcionou ao autor sênior os meios necessários para execução do trabalho. À bióloga Karen Schmidt e aos técnicos da Embrapa Cerrados Wellington Cavalcanti, pelo auxílio com o programa de tratamento das figuras, e Jânio Fonseca Silva que providenciou os materiais e equipamentos necessários aos trabalhos de laboratório.

\section{REFERÊNCIAS BIBLIOGRÁFICAS}

Beutelspacher, C. 1967. Estudio morfologico de Erinnys ello (Linnaeus, 1758) (Lepidoptera, Sphingidae). Anales del Instituto de Biología de la Universidad Nacional Autónoma de México, Série Zoología, México, 38 (1): 59-74. 
Bizarro, J.M.S.; M.M. Casagrande \& O.H.H. Mielke. 2003. Morfologia externa de Thyridia psidii cetoides (Rosenberg \& Talbot) (Lepidoptera, Nymphalidae, Ithomiinae). II. Tórax e apêndices. Revista Brasileira de Zoologia, Curitiba, 20 (3): 419-425.

Camargo, A.J.A. de; M.M. Casagrande; O.H.H. Mielke \& E. FurtaDo. 2005. Morfologia externa do adulto de Almeidaia aidae Mielke \& Casagrande (Lepidoptera, Saturniidae, Arsenurinae, Almeidaiini). I. Cabeça, apêndices e região cervical. Revista Brasileira de Zoologia, Curitiba, 22 (3): 619-622.

Casagrande, M.M. 1979a. Sobre Caligo beltrao (Illiger).II: Morfologia externa da cabeça do adulto (Lepidoptera, Satyridae, Brassolinae). Revista Brasileira de Biologia, Rio de Janeiro, 39 (1): 223-227.

Casagrande, M.M. 1979b. Sobre Caligo beltrao (Illiger).III: Morfologia externa do adulto - tórax (Lepidoptera, Satyridae, Brassolinae). Revista Brasileira de Biologia, Rio de Janeiro, 39 (2): 347-355.

Сомsтоск, J.H. 1918. The wings of Lepidoptera, p. 319-346. In: J.H.Сомsтоск (Ed.) The wings of insects. New York, Ithaca, $\mathrm{XXIII+430p.}$

Gagarin, P. 1966. Sobre o exemplar feminino de "Almeidaia romualdoi" Travassos, 1937. Atas da Sociedade de Biologia do Rio de Janeiro 10 (4): 95.

Recebido em 30.IV.2004; aceito em 22.XI.2005.
Hogue, C.L. 1963. A standard method for mounting whole adult Lepidoptera on slides utilizing polystyrene plastic. Journal of Research on the Lepidoptera, Beverly Hills, 1 (3): 223235.

Lemaire, C. 1971. Révision du genre Automeris Hübner et dês genres voisins. Biogéographie, éthologie, morphologie, taxonomie (Lep. Attacidae). Mémoires du Muséum National D'Histoire Naturelle, Paris, 68 (fascicule unique): 1-576.

Lemaire, C. 1980. Les Attacidae Américains ( = Saturniidae). Arsenurinae. Édition C. Lemaire, Neuilly-sur-Seine, 199p.

MAdDEN, A.H. 1944. The external morphology of the adult tobacco hornworm (Lepidoptera, Sphingidae). Annals of the Entomological Society of America, New York, 27 (2): 145-160.

Michener, C.D. 1952. The Saturniidae (Lepidoptera) of the Western Hemisphere, morphology, phylogeny, and classification. Bulletin of the American Museum of Natural History, New York, 98 (5): 335-502.

Mielke, O.H.H \& M.M. Casagrande. 1981. Notas sobre o gênero Almeidaia Travassos, com descrição de uma espécie nova (Lepidoptera, Saturniidae, Arsenurinae). Revista Brasileira de Biologia, Rio de Janeiro, 41 (4): 809-813.

Robinson, G.S. 1976. The preparation of slides of Lepidoptera genitalia with special reference to the microlepidoptera. Entomologists Gazette, Northamptonshire, 27: 127-132. 